\title{
Cluster Preface: Progress in Organo-Fluorine Chemistry
}

\author{
Duncan L. Browne* \\ School of Chemistry, Cardiff University, Main Building, Park Place, \\ Cardiff, CF10 3AT, UK \\ DLBrowne@cardiff.ac.uk
}

Received: 30.09 .2014

Accepted: 01.10.2014

Published online: 17.12 .2014

DOI: 10.1055/s-0034-1379721; Art ID: st-2014-I2001-c

Abstract The chance of achieving a successful 'hit' in the search for new and improved functional organic molecules can be increased by appropriate fluorination. To this end, many new and exciting methods for the site-selective, controlled fluorination of organic molecules are being developed. This Cluster contains a series of articles that represent the most recent achievements in this field.

Key words fluorination, organo-fluorine, selectivity, improved physical properties, isotopic labelling, materials science

The presence of fluorine in organic molecules can improve or enhance the desirable characteristic properties of materials that serve society. ${ }^{1}$ For example, the application of polyfluorinated organic compounds ranges from important monomeric gases such as anaesthetics and refrigerants to 'non-stick' polymeric solid substances such as Teflon (Figure 1). Whereas judicious choice of where to fluorinate more complex organic molecules can enhance the desirable properties of healthcare and agricultural products, ${ }^{2}$ it has been found that the subtle, strategic and site-selective introduction of fluorine into biologically active organic compounds can lead to both dramatic and fine tuning changes in properties. Here, fluorine can affect $\mathrm{p} K_{\mathrm{a}}$ values and therefore binding affinities, pharmacokinetics and the bioavailability of substances. ${ }^{3}$ Selective and appropriate fluorination can also increase the half-life and dosing rates of biologically active molecules by reducing the potential for metabolism through oxidation of $\mathrm{C}-\mathrm{H}$ bonds. Clearly, this leads to patients or crops being dosed less frequently and in smaller quantities.

Radiolabelled compounds bearing 'hot' fluorine or ${ }^{18} \mathrm{~F}$, such as $\left[{ }^{18} \mathrm{~F}\right]-F D G$ (2-fluorodeoxyglucose) and $\left[{ }^{18} \mathrm{~F}\right]$-fluoroL-dopa enable positron emission tomography (PET) scanning and are critical to the early diagnosis of the onset of Alzheimer's or Parkinson's disease. ${ }^{4}$ Alternatively, nonradiolabelled, 'cold' fluorine or ${ }^{19} \mathrm{~F}$ compounds can be used for medical diagnostics through ${ }^{19} \mathrm{~F}$-magnetic resonance imaging (MRI). ${ }^{5}$ Importantly for synthesis, fluorine can be used as a control element in asymmetric reactions, where strategic placement provides a desirable gauche effect, leading to the enhancement of conformational rigidity of stereo-defining transition states, resulting in improvements in enantioselectivity. ${ }^{6}$ This particular effect has been ex-

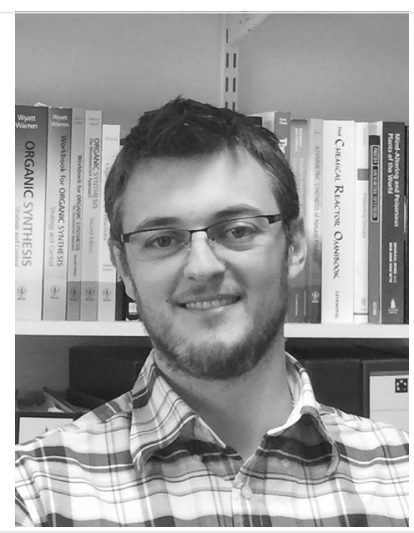

Duncan Browne studied Chemistry with Study in Industry, at the University of Sheffield (with a placement at GSK) graduating in 2006. He obtained his $\mathrm{PhD}$ in 2009 from the same institution under the guidance of Prof. Joe Harrity and in collaboration with Syngenta. Following a one year EPSRC Doctoral Prize Fellowship, in 2010 he joined Prof Steve Ley FRS CBE at the University of Cambridge. In 2012, he was appointed as a college teaching associate at Sidney Sussex College prior to joining the college fellowship and becoming director of studies. In 2014, Duncan was appointed as a Lecturer in Organic Chemistry at Cardiff University. His current research interests include the development of methods to access under-represented organo-fluorine motifs, the development of continuous flow processing techniques, and the exploration of mechano-chemical methods for synthetic chemistry.

plored in detail in the context of amine-based organocatalysis. Furthermore, by appropriate fluorination of phenyl groups, fluorine can be used to enhance noncovalent, $\pi-\pi$ stacking interactions in asymmetric processes mediated by organocatalytic BINOL-derived phosphoric acids. ${ }^{7}$

This brief survey, covering just a few of the known effects that fluorine can impart to organic structures, demonstrates the power and importance of this combination. Undoubtedly, these effects are ultimately attributable to the large electronegativity of fluorine. However, a dichotomy exists whereby the extreme nature of this electronegativity leads to a very high reactivity of its elemental form, a trait that is not appropriate for the selective decoration of designed organic architectures. This high reactivity poses many safety issues and consequently limits the use of $F_{2}$ gas to reactions conducted in specialised equipment by suitably trained personnel. Clearly such a restriction is not congruent with the research and discovery of molecules, where convenience of use and generality of a process are generally sought. In this context, since early observations of the syn- 


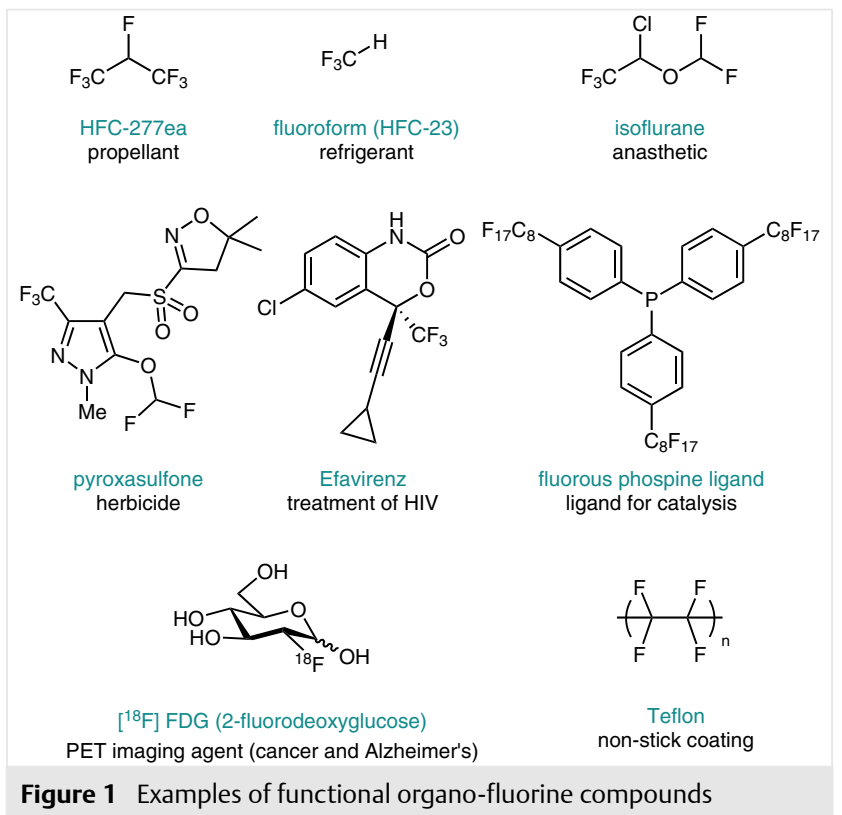

ergy, the focus has been shifting towards methods that are straightforward to execute and pose a minimal, or greatly reduced safety hazard, whilst delivering absolute control and selectivity over the transformation. This is largely being achieved in two distinct ways: (1) by starting with appropriately fluorinated functionalized buildings blocks and using these to build up complexity, or (2) by the late-stage introduction of fluorine or fluorinated motifs directly on to the molecule of interest.

The discovery and furtherance of late-stage fluorination approaches has been greatly facilitated by the development of new fluorinating agents that are inherently safer and easier to manipulate than the likes of fluorine gas, hydrofluoric acid, sulfur tetrafluoride or hyperfluorous acid. Some notable examples of these reagents are shown in Figure 2, together with the year in which they were reported. ${ }^{8-19}$

Whilst it is true that some fluorinating agents begin to look exotic and expensive, they merely serve a purpose for the discovery of new molecules, often this is done with a late-stage 'fluorine scan'. Not every fluorination is going to give a 'better' molecule; in fact, it is quite the opposite, which is perhaps part of the excitement! Once the appropriate fluorination has been identified and the molecule is ready for development then one can revert back to the robust methods to create the appropriate building block for manufacture. Indeed, much of this chemistry can be outsourced to companies that specialise in the large-scale manufacture of fluorinated building blocks employing such hazardous fluorinating materials.

In conclusion, the ability to selectively fluorinate organic molecules is of paramount importance to the discovery of new molecules that possess superior performance compared with their non-fluorinated counterparts. As such,

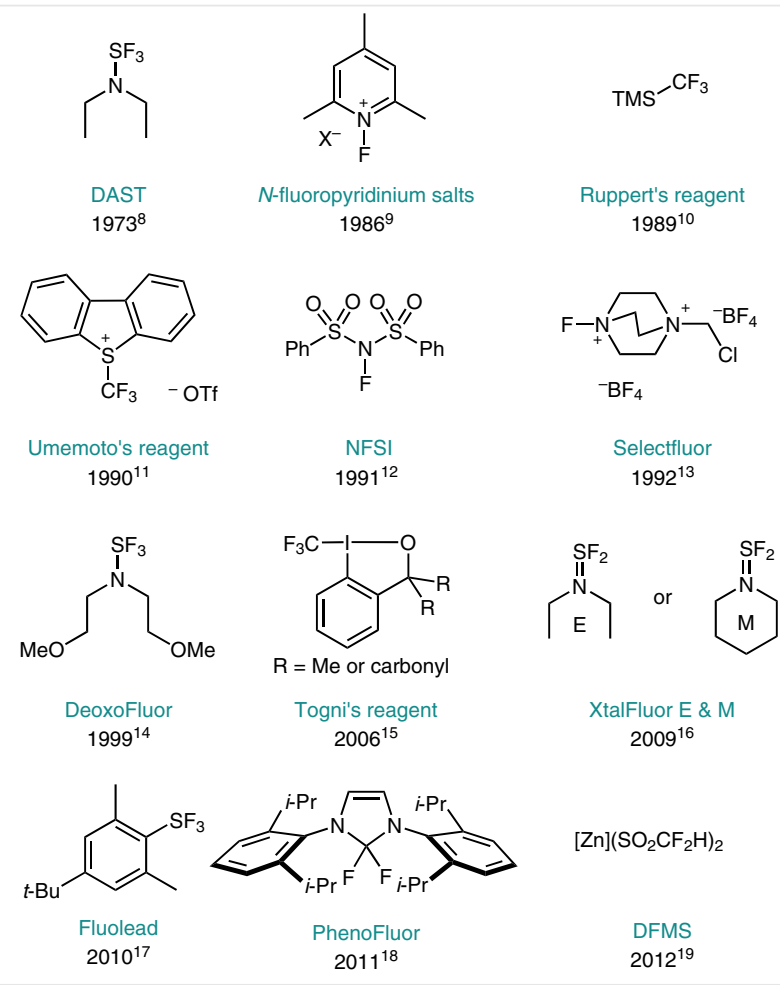

Figure 2 Examples of designed fluorinating agents for the selective and controlled fluorination of organic molecules

organo-fluorine chemistry is becoming a centre-piece for new reaction discovery and method development. These are exciting times for organic chemistry in general. We are seeing the development and use of new reaction manifolds such as photo-redox chemistry, ${ }^{20}$ innate $\mathrm{C}-\mathrm{H}$ activation, ${ }^{19,21}$ multiple-bond-forming cascades, ${ }^{22}$ photo-flow chemistry ${ }^{23}$ and the use of computational methods to rationally design bespoke ligands. ${ }^{24}$ It is a great pleasure to bring together some of the recent advances in this important field from across the globe for this Cluster.

\section{References}

(1) (a) Kirsch, P. Modern Fluoroorganic Chemistry, 2nd ed.; WileyVCH: Weinheim, 2013. (b) Liang, T.; Neumann, C. N.; Ritter, T. Angew. Chem. Int. Ed. 2013, 52, 8214. (c) O'Hagan, D. Chem. Soc. Rev. 2008, 37, 308.

(2) (a) Kirk, K. L. J. Fluorine Chem. 2006, 127, 1013. (b) Purser, S.; Moore, P. R.; Swallow, S.; Gouverneur, V. Chem. Soc. Rev. 2008, 37, 320. (c) Jeschke, P. ChemBioChem 2004, 5, 570.

(3) (a) Böhm, H. J.; Banner, D.; Bendels, S.; Kansy, M.; Kuhn, B.; Müller, K.; Obst-Sander, U.; Stahl, M. ChemBioChem 2004, 5, 637. (b) Müller, K.; Faeh, C.; Diederich, F. Science 2007, 317, 1881. (c) Morgenthaler, M.; Schweizer, E.; Hoffmann-Röder, A.; Benini, F.; Martin, R. E.; Jaeschke, G.; Wagner, B.; Fischer, H.; Bendels, S.; Zimmerli, D.; Schneider, J.; Diederich, F.; Kansy, M.; Müller, K. ChemMedChem 2007, 2, 1100. 
(4) Miller, P. W.; Long, N. J.; Vilar, R.; Gee, A. D. Angew. Chem. Int. Ed. 2008, 47, 8998.

(5) Ruiz-Cabello, J.; Barnett, B. P.; Bottomley, P. A.; Bulte, J. W. M. NMR Biomed. 2011, 24, 114.

(6) (a) Sparr, C.; Schweizer, W. B.; Senn, H. M.; Gilmour, R. Angew. Chem. Int. Ed. 2009, 48, 3065. (b) For an overview of the influence of fluorine in asymmetric catalysis, see: Cahard, C.; Bizet, V. Chem. Soc. Rev. 2014, 43, 135.

(7) Lv, J.; Zhang, L.; Hu, S.; Cheng, J.-P.; Luo, S. Chem. Eur. J. 2012, 18, 799.

(8) Markovskij, L. N.; Pashinnik, V. E.; Kirsanov, A. V. Synthesis 1973, 787.

(9) Umemoto, T.; Tomita, K. Tetrahedron Lett. 1986, 27, 3271.

(10) (a) Ruppert, I.; Schlich, K.; Volbach, W. Tetrahedron Lett. 1984, 25, 2195. (b) Prakash, G. K. S.; Krishnamurti, R.; Olah, G. A. J. Am. Chem. Soc. 1989, 111, 393.

(11) (a) Yagupolskii, L. M.; Kondratenko, N. V.; Temofeeva, G. N. J. Org. Chem. USSR 1984, 20, 103. (b) Umemoto, T.; Ishihara, S. Tetrahedron Lett. 1990, 31, 3579.

(12) (a) Barnette, W. E. J. Am. Chem. Soc. 1984, 106, 452. (b) Singh, S.; DesMarteau, D. D.; Zuberi, S. S.; Witz, M.; Huang, H. N. J. Am. Chem. Soc. 1987, 109, 7194. (c) Differding, E.; Ofner, H. Synlett 1991, 187.

(13) Banks, R. E.; Mohialdin-Khaffaf, S. N.; Lal, G. S.; Shariff, I.; Syvret, R. G. J. Chem. Soc., Chem. Commun. 1992, 595.

(14) Lal, G. S.; Pez, G. P.; Pesaresi, R. J.; Prozonic, F. M. Chem. Commun. 1999, 215.
(15) Eisenberger, P.; Gischig, S.; Togni, A. Chem. Eur.J. 2006, 12, 2579.

(16) Beaulieu, F.; Beauregard, L.-P.; Courchesne, G.; Courturier, M.; LaFlamme, F.; L'Heureux, A. Org. Lett. 2009, 11, 5050.

(17) Umemoto, T.; Singh, R. P.; Xu, Y.; Saito, N. J. Am. Chem. Soc. 2010, 132,18199

(18) Tang, P.; Wang, W.; Ritter, T. J. Am. Chem. Soc. 2011, 133, 11482.

(19) Fujiwara, Y.; Dixon, J. A.; Rodriguez, R. A.; Baxter, R. D.; Dixon, D. D.; Collins, M. R.; Blackmond, D. G.; Baran, P. S. J. Am. Chem. Soc. 2012, 134, 1494.

(20) (a) Nagib, D. A.; Scott, M. E.; MacMillan, D. W. C. J. Am. Chem. Soc. 2009, 131, 10875. (b) Nagib, D. A.; MacMillan, D. W. C. Nature 2011, 480, 224. (c) Ye, Y.; Sanford, M. S. J. Am. Chem. Soc. 2012, 134, 9034.

(21) (a) Lie, W.; Huang, X.; Cheng, M.-J.; Nielsen, R. J.; Goddard, W. A. III; Groves, J. T. Science 2012, 337, 1322. (b) Fujiwara, Y.; Dixon, J. A.; O'Hara, F.; Funder, E. D.; Dixon, D. D.; Rodriquez, R. A.; Baxter, R. D.; Herlé, B.; Sach, N.; Collins, M. R.; Ishihara, Y.; Baran, P. S. Nature 2012, 492, 95.

(22) Zhang, B.; Studer, A. Org. Lett. 2014, 16, 1216.

(23) (a) Straathof, N. J. W.; Gemoets, H. P. L.; Wang, X.; Schouten, J. C.; Hessel, V.; Noël, T. ChemSusChem 2014, 7, 1612. (b) Cantillo, D.; deFrutos, O.; Rincon, J. A.; Mateos, C.; Kappe, C. O. J. Org. Chem. 2014, 79, 8486.

(24) (a) Nielsen, M. C.; Bonney, K. J.; Schoenebeck, F. Angew. Chem. Int. Ed. 2014, 53, 5903. (b) Anstaett, P.; Schoenebeck, F. Chem. Eur. J. 2011, 17, 12340. (c) Grushin, V.; Marshall, W. J. J. Am. Chem. Soc. 2006, 128, 12644. 